\title{
Detección de Poliovirus en Aguas Residuales de Armenia, Colombia
}

\author{
María M. González ${ }^{1}$, Luís Sarmiento ${ }^{2}$, Jhon Carlos Castaño ${ }^{3}$, Alejandra M. Giraldo ${ }^{4}$, \\ Alexander Salazar ${ }^{5}$ Y Nini J. Muñoz \\ ${ }^{1}$ Licenciada en Enfermería. Especialista en Epidemiología. Centro de Investigaciones Biomédicas. \\ Facultad Ciencias de la Salud. Universidad del Quindío. E-mail: mechotas2004@yahoo.com \\ ${ }^{2}$ Licenciado en Microbiología. M. Sc. Virologia. Departamento Virología. Instituto de Medicina Tropical \\ Pedro Kourí. La Habana, Cuba. E-mail: sarmiento@ipk.sld.cu \\ ${ }^{3}$ Médico Ph. D. Ciencias Básicas Médicas.Centro de Investigaciones Biomédicas. Facultad de Ciencias \\ de la Salud. Universidad del Quindío. E-mail: jhoncarlos@uniquindio.edu.co \\ ${ }^{4}$ Bióloga. Centro de Investigaciones Biomedicas. Facultad de Ciencias de la Salud. Universidad del \\ Quindío. E-mail: amagiga2001@yahoo.com \\ ${ }^{5}$ Ingeniero Agrónomo. Especialista en gestión ambiental. Fundación Semillas de Vida. Armenia, \\ Colombia..E-mail: alexsas@telesat.com.co \\ ${ }^{6}$ Administradora de Empresas Agropecuarias. E-mail: naturalniny21@yahoo.com.mx
}

Recibido 11 Octubre 2005/Enviado para Modificación 19 Marzo 2006/Aceptado 10 Abril 2006

\section{RESUMEN}

Objetivos Implementar un método para la vigilancia ambiental de poliovirus circulante a partir de aguas residuales.

Métodos Se colectaron 6 muestras de aguas residuales en los sitios finales de descarga del acueducto de Armenia, Quindío. Los virus fueron concentrados y extraídos por un método que usa el polietilenglicol y cloruro de sodio como agentes concentradores. La identificación de poliovirus se realizó mediante la técnica de reacción en cadena de la polimerasa empleando cebadores específicos de grupo, de serotipo y de cepa vacunal sabin.

Resultados Se demostró la eficiencia de los métodos de detección viral empleados. Se encontró la presencia de poliovirus en 5 de las 6 (83\%) muestras colectadas. La identificación serotipo-específica reveló la presencia de poliovirus tipo 1 y 3 en las muestras estudiadas. Todos los poliovirus detectados resultaron ser del tipo vacunal lo cual aporta una evidencia más a favor de la no circulación de poliovirus salvaje en la región.

Conclusión El sistema de vigilancia a partir de aguas residuales puede ser una herramienta sensible para la detección de la circulación de poliovirus.

Palabras Clave: Aguas residuales, reacción en cadena de la polimerasa, poliovirus, Colombia (fuente: DeCS, BIREME).

\section{ABSTRACT \\ Detecting poliovirus in wastewater from Armenia, Colombia}


Objectives Implementing environmental surveillance for poliovirus circulating from wastewater.

Methods Six wastewater samples were collected from each final site within a wastewater collection system in Armenia, Quindío. Virus was extracted and concentrated by a method using polyethylenglycol and sodium chloride as concentrating agent. Polioviruses were identified by polymerase chain reaction assay with group-specific, serotype-specific and Sabin vaccine-specific primers.

Results It was confirmed that the viral detection method is highly efficient. Poliovirus was detected in 5 of 6 (83\%) samples collected. Serotype-specific identification revealed the presence of type 1 and type 3 polioviruses in the samples. All of them were of the vaccine type, which provided evidence regarding the non-circulation of wild poliovirus in the country.

Conclusion Wastewater surveillance can be a sensitive tool for detecting poliovirus circulation.

Key Words: Sewage, polymerase chain reaction, poliovirus, Colombia (source: $M e S H, N L M$ ).

L

a poliomielitis es una enfermedad causada por los 3 serotipos del virus de la polio, considerados estos como los virus prototipos del gé-

nero enterovirus. Afecta fundamentalmente a los niños menores de 5 años de edad y dentro de sus manifestaciones clínicas más graves se encuentra la parálisis, la cual tiende a persistir por toda la vida (1). La intensa batalla por su erradicación condujo a la valiosa obtención, producción y aplicación de vacunas virales inactivadas y vivas atenuadas, que redujeron marcadamente la incidencia de poliomielitis en todo el mundo (2). En 1988, la Organización Mundial de la Salud se propuso la tarea de erradicar la poliomielitis. Desde entonces, la iniciativa para la erradicación de la polio ha reportado un drástico progreso en la disminución de la incidencia de esta enfermedad, confinándose el poliovirus salvaje a la región del Sudeste Asiático y algunos países Africanos (3).

En 1994 la región de las Américas y todo el hemisferio Occidental recibió la certificación de estar libre de poliovirus salvaje. Actualmente, sólo las cepas vacúnales con su consiguiente carácter atenuado parecen circular en estas regiones reemplazando al poliovirus salvaje. Sin embargo, se conoce que las cepas de poliovirus vacunal al replicarse en el tracto intestinal y circular en la población tienden a revertir a las cepas salvajes que les dieron origen. De esta forma podrían producirse brotes epidémicos de la enfermedad producido por cepas "modificadas" originadas de las vacúnales que cir- 
culan en una población susceptible que se haya acumulado producto de las bajas coberturas de inmunidad (4).

Recientemente ha sido demostrado que los virus derivados de la vacuna han circulado en una forma virulenta y han causado epidemias de poliomielitis en países como República Dominicana (5) y Haití (6), Filipinas (7) y Madagascar (8). Estos hallazgos apuntan hacia la necesidad de reforzar la vigilancia ambiental de la circulación de poliovirus pues la detección temprana de poliovirus derivados de la vacuna es crítica para lograr una respuesta efectiva a estos brotes ; en Latinoamérica a excepción de Cuba no se han reportado a la fecha estudios de vigilancia ambiental de poliovirus en aguas residuales. La detección de poliovirus en las aguas residuales puede brindar una información muy valiosa sobre la circulación de estos virus en la comunidad ya que cantidades abundantes de poliovirus son excretadas en las heces fecales de las personas inmunizadas y las aguas residuales pueden actuar como un vehículo de infección con las cepas vacunales (9).

\section{MATERIALES Y MÉTODOS}

Área de estudio

Está ubicada en la zona urbana del municipio de Armenia, Departamento del Quindío - Colombia, con las siguientes características:

Área : $236,2 \mathrm{Kms}^{2}$

Población: $\quad 350.000$ habitantes según el censo de 1993.

Clima: $\quad$ Medio húmedo.

Altura: $\quad 1200$ a 2000 metros sobre el nivel del mar

Época de lluvias: $\quad$ Marzo a Mayo y Septiembre a Noviembre Época de verano: Junio a Agosto y Diciembre a Febrero.

Temperatura: $\quad 18$ a $24{ }^{\circ} \mathrm{C}$

Zona de Vida: $\quad$ Bosque muy húmedo premontano (bmh-PM)

Precipitación promedio:2 000 a 4000 milímetros año

Humedad relativa: $\quad 80 \%$

Muestra

Se colectaron 6 muestras de aguas residuales a razón de 1 litro por cada punto de recogida los cuales fueron seleccionados en los sitios finales de descarga del alcantarillado de Armenia. Los puntos de muestreo correspon- 
dieron a las microcuencas de Hojas Anchas, Río Quindio, La Aldana San Nicolás, La Aldana, La Florida, y Paujil. El periodo de recolección de las muestras estuvo comprendido entre el 20 de agosto y el 3 de septiembre del 2005. A cada una de las muestras se le realizó determinación de $\mathrm{pH}$, turbiedad, sólidos suspendidos totales, coliformes totales, coliformes fecales y concentración de oxigeno.

Se colectaron además dos muestras de 1 litro de agua cada una en el punto de nacimiento de la quebrada La Aldana donde no existe la posibilidad de circulación de poliovirus. Como control positivo a una de ellas se le adicionó $1 \mathrm{~mL}$ de la vacuna oral trivalente de poliovirus atenuado (OPV, Polioral ${ }^{\mathrm{TM}}$, Chiron/Vaccines ${ }^{\mathrm{TM}}$ ). La otra muestra fue empleada como control negativo.

Recuperación de virus de aguas residuales

La recuperación y concentración de virus en aguas residuales e realizó según los principios generales del método descrito por Sobsey $(10,11)$. De manera general este método consiste en una separación inicial de los sólidos contenidos en la muestra, tratados dos veces con extracto de carne a $3 \%$ y cloroformo para eluir partículas virales asociadas con material orgánico. El material obtenido de este tratamiento se unió con la muestra original y los virus fueron precipitados de esta solución con cloruro de sodio $0,3 \mathrm{~N}$ y polietilenglicol al $8 \%$. Por último, el sedimento fue resuspendido con tampón fosfato salino (PBS) y extracto de carne a 3\% para obtener el virus concentrado en un volumen final de $6 \mathrm{ml}$.

Oligonucleótidos sintéticos (cebadores)

Se emplearon 3 juegos de cebadores:

a. Cebadores específicos del grupo de los poliovirus (Pan PV) que permiten la amplificación de una secuencia de 79 pares de bases (pb) común los 3 serotipos de poliovirus (12).

b. Cebadores específicos de serotipo (PV) que permiten la amplificación de una secuencia de 70, 79 y 140 pb de las cepas tanto vacunales como salvajes de los serotipos de poliovirus 1,2 y 3 respectivamente (13).

c. Cebadores específicos de las cepas vacunales (Sabin) que permiten la amplificación de una secuencia de 97 pb, 71 pb, y 44 pb de la cepa vacunal Sabin 1, Sabin 2 y Sabin 3 respectivamente, excluyendo la amplificación cruzada con genotipos de poliovirus salvajes (14). 


\section{Extracción de Ácidos Nucleicos}

La extracción de Ácido Ribonucleico (ARN) a partir de las muestra de aguas residuales concentrada se realizó empleando el estuche comercial Nucleospin ${ }^{\circledR}$ Virus kit BD Biosciences siguiendo las instrucciones del fabricante.

\section{Amplificación de Ácidos Nucleicos}

La Reverso Transcripción y la Reacción en Cadena de la Polimerasa (RTRCP) se realizaron siguiendo los principios generales del método aplicado por Kilpatrick (12). Se tomaron cada uno de los cebadores se adicionaron a una mezcla de reacción, preparada en un volumen de $50 \mu \mathrm{L}$, que contenía tampón de amplificación 10X (tris HCl 67 mM y pH 8,8, NH4SO4 17 mM, EDTA $6 \mu \mathrm{M}, \mathrm{MgCl} 22 \mathrm{mM}$, 2-mercaptoetanol, 1mM), $100 \mu \mathrm{M}$ de cada deoxinucleótido trifosfatado (dATP, dGTP, dCTP, dTTP), 5 Uds de inhibidor de Rnasa, 16 Uds de Transcriptasa Inversa AMV, 1,26 Uds de Taq ADN Polimerasa. A cada tubo de reacción se le añadió $5 \mu \mathrm{L}$ de ARN previamente extraído.

Los tubos fueron puestos en un termociclador (MJ Research, PTC100 ${ }^{\circledR}$ ) a las temperaturas de $42^{\circ} \mathrm{C}$ durante 20 minutos (min), para la transcripción inversa, a lo que siguieron 30 ciclos con temperaturas de $95^{\circ} \mathrm{C}$ por 45 segundos (s), $42^{\circ} \mathrm{C}$ por $45 \mathrm{~s}$ y $60^{\circ} \mathrm{C}$ durante $45 \mathrm{~s}$, finalmente la mezcla de reacción se dejó durante 5 min a $60^{\circ} \mathrm{C}$.

Para la detección del producto amplificado se tomaron $10 \mu \mathrm{L}$ del producto de la RT-RCP a los que se añadieron $2 \mu \mathrm{L}$ de tampón para muestra de electroforesis (azul de bromofenol al 0,2\%, xilene-cianol al 0,2 \% y sacarosa al $40 \%)$. La mezcla se sometió a corrida electroforética en gel de poliacrilamida (acrilamida-NN' metilenbisacrilamida 30:1) no desnaturalizante al $15 \%$ en TBE (Tris-Borato 0,09 M, EDTA 2 mM) 1x PH 8, a 10 V/cm durante 2 horas. Terminada la corrida, el gel se tiñó con solución acuosa de bromuro de etidio a $5 \mu \mathrm{g} / \mathrm{mL}$ por 5 min y se lavó 2 veces con agua destilada. Las bandas de ADN fluorescentes se visualizaron en un transiluminador de luz ultravioleta. En cada corrida se utilizó el marcador de peso molecular DNA leader (DNA ladder INVITROGEN ${ }^{\circledR}$ ).

Para la disminución de los riesgos de contaminación en cada ensayo se asumió un grupo de medidas semejantes a las descritas por Kitchin y Bootman (15). 


\section{RESULTADOS}

Los diferentes parámetros medidos en las aguas colectadas se muestran en la Tabla 1. Los resultados de la detección de poliovirus presentes en las muestras de aguas residuales estudiadas mediante RT-RCP se muestran en la Tabla 2 y se resumen a continuación:

Tabla 1. Parámetros medidos en cada microcuenca del municipio de Armenia (punto de muestreo). Agosto de 2005

\begin{tabular}{|c|c|c|c|c|c|c|c|c|}
\hline \multirow{2}{*}{ Microcuena } & \multicolumn{8}{|c|}{ Parámetros } \\
\hline & $\mathrm{pH}$ & Turbiedad & $\begin{array}{l}\text { Sólidos } \\
\text { suspend. } \\
\text { totales }\end{array}$ & $\begin{array}{l}\text { Coliformes } \\
\text { totales }\end{array}$ & $\begin{array}{l}\text { Coliformes } \\
\text { fecales }\end{array}$ & OD* & $\begin{array}{l}\text { DQO } \\
\star \star\end{array}$ & $\begin{array}{l}\text { DBO } \\
\star \star \star\end{array}$ \\
\hline $\begin{array}{l}\text { Hojas } \\
\text { Anchas }\end{array}$ & 7.00 & 28 UNT & 18 & $>24 \times 107$ & $>24 \times 107$ & 2.6 & 87 & 79 \\
\hline Rio Quindio & 7.0 & 7 UNT & 10 & $>24 \times 105$ & $>24 \times 105$ & 6.1 & 23 & 13 \\
\hline $\begin{array}{l}\text { La Aldana- } \\
\text { S.N }\end{array}$ & 6.80 & 14 UNT & 15 & $>24 \times 106$ & $11 \times 106$ & 5.1 & 109 & 39 \\
\hline La Aldana & 6.96 & 82 UNT & 58 & $>24 \times 107$ & $>24 \times 107$ & 3.0 & 222 & 217 \\
\hline La Florida & 7.10 & 11 UNT & 17 & $>24 \times 106$ & $11 \times 108$ & 7.1 & 46 & 29 \\
\hline Paujil & 7.05 & 4 UNT & $<$ LD 4 & 40000 & 30000 & 6.7 & 12 & $<\mathrm{LD}^{3}$ \\
\hline
\end{tabular}

Tabla 2. Identificación de poliovirus en las aguas residuales empleando cebadores de grupo (Pan PV), específicos de serotipo (PV) y de cepas vacunales (Sabin).

\begin{tabular}{lllllllll}
\hline No & Localidad & Grupo & Serotipo 1 & Serotipo 2 & \multicolumn{2}{c}{ Serotipo 3 } \\
\hline & & Pan & PV1 & Sabin & PV2 & Sabin & PV3 & $\begin{array}{l}\text { Sabin } \\
2\end{array}$ \\
\hline 1 & & PV & & 1 & & 2 & & 3 \\
\hline 2 & Hojas Anchas & + & + & + & - & - & - & - \\
\hline 3 & Río Quindío & + & + & + & - & - & + & + \\
\hline 4 & La Aldana- S. N & - & - & - & - & - & - & - \\
\hline 5 & La Aldana & + & - & - & - & - & + & + \\
\hline 6 & La Florida & + & + & + & - & - & - & - \\
\hline $\begin{array}{l}\text { Control } \\
\text { Positivo }\end{array}$ & Universidad & + & + & + & + & + & + & + \\
\hline $\begin{array}{l}\text { Control } \\
\text { Negativo }\end{array}$ & Universidad & - & - & - & - & - & - & - \\
\hline
\end{tabular}


- Se comprobó la eficiencia de los métodos de detección viral empleados al obtenerse resultados positivos con todos los juegos de cebadores en la muestra control positivo.

- Se obtuvieron bandas de amplificación de 79 pb con los cebadores específicos del grupo de poliovirus en el $83 \%$ (5/6) de las muestras procesadas.

- Se identificaron en total cuatro poliovirus tipo 1 y dos poliovirus tipo 3. En una de las 5 muestras que resultaron positivas a poliovirus se identificó la presencia de mezcla de los serotipos 1 y 3 . No se encontró poliovirus tipo 2 en ninguna de las muestras estudiadas.

- Todos los poliovirus encontrados resultaron ser del tipo vacunal.

\section{DISCUSIÓN}

Para estudiar el comportamiento de los poliovirus en el ambiente, en el presente trabajo se utilizó un método de detección viral a partir de aguas residuales y la identificación viral mediante reacción en cadena de la polimerasa.

Para realizar este estudio seleccionamos el municipio de Armenia, Quindio pues este cuenta con una cobertura del $95 \%$ en vacunación con OPV, mediante el empleo de programas mantenidos de inmunización durante todo el año. Cada niño recibe una primera dosis al nacimiento (dosis cero), y luego tres dosis que se inicia a los dos meses de edad con intervalos mínimos de 4 semanas (cuatro dosis en el año). Posteriormente a los 18 meses reciben una quinta dosis después de un año de la última dosis y refuerzo a los cinco años. Como resultado de la aplicación de este sistema de vacunación los poliovirus vacunales deben circular durante todo el año en la comunidad.

El periodo de recolección de las muestras estuvo enmarcado en la segunda quincena del mes de agosto por corresponder al periodo seco en la localidad de Armenia. De esta forma se aumenta la posibilidad de detección de poliovirus en las aguas residuales al evitar la dilución de las mismas con las agua provenientes de los periodos de lluvia.

Para evaluar el método de recuperación viral empleamos como control positivo una muestra de agua a la cual le adicionamos la vacuna trivalente de 
poliovirus vivo atenuado que se emplea de rutina en el país. Con los resultados obtenidos demostramos que los métodos empleados para el estudio de las aguas brindan la posibilidad de recuperar y detectar poliovirus presentes en la muestra, lo que constituye una valiosa herramienta en la vigilancia ambiental.

La detección de poliovirus en 5 de las 6 (83\%) aguas estudiadas indica que el sistema de vigilancia a partir de las aguas residuales puede ser un método sensible para la detección de la circulación de poliovirus. Los valores obtenidos de los parámetros medidos en cada uno de los puntos de muestreo proporcionan condiciones favorables para la circulación de virus y reducen la posibilidad de inhibición de la detección viral por condiciones ambientales específicas adversas. Sin embargo, el punto donde no se detectó circulación poliovirus recibe residuos de hidrocarburos de una estación de gasolina y por tanto la posible presencia en las aguas de compuestos orgánicos y fenólicos, metales pesados, y otras sustancias inorgánicas provenientes de esta fuente de contaminación pudieron haber provocado interferencia en la extracción de ARN, degradarlos o impedir la actividad de las enzimas necesarias para la detección de genomas virales en la muestra $(16,17)$.

Estudios previos en Cuba empleando métodos similares a los nuestros reportaron presencia de poliovirus en el $100 \%$ de las aguas residuales estudiadas. Sin embargo, hay que señalar que estos porcentajes se obtuvieron a las 3 y 4 semanas después de concluida las campañas de vacunación masiva con OPV que se realizan en Cuba (9). Como resultado de las campañas masivas de inmunización circulan en corto tiempo una gran cantidad de poliovirus en el ambiente y por tanto los niveles de circulación de poliovirus en el momento en que se realizó el estudio en Cuba son mayores que los que puedan existir en Colombia donde la vacunación no es en campañas masivas. Teniendo en cuenta esta diferencia en los niveles de circulación los resultados de nuestro estudio sustentan la alta sensibilidad del método de detección viral a partir de aguas residuales para monitorear la circulación de poliovirus. Esta afirmación es atribuible al hecho de que en las aguas residuales convergen los virus eliminados por las heces fecales de toda la población lo que ha permitido estimar que las aguas residuales son 100 veces más sensibles que las heces fecales para detectar excreción de virus (18).

La identificación y diferenciación intratípica de los poliovirus detectados mediante RT-RCP demostraron el carácter vacunal de los poliovirus circulantes, lo cual constituye un fuerte argumento a favor de la no circulación de poliovirus salvajes en la región. Se conoce que los aislamientos asociados con la vacunación pueden diferir marcadamente de la cepa parental, debido a 
que el paso y multiplicación en el intestino puede provocar frecuentes cambios genéticos y antigénicos (19, 20, 21, 22). Sin embargo, los cambios genéticos que puedan surgir como resultado de la replicación natural de los poliovirus vacunales no interfieren con la adecuada identificación con los cebadores empleados, debido a la internalización de la zona escogida. Por tanto, para conocer la variación mutacional de los poliovirus detectados y la posible circulación de poliovirus derivados de la vacuna en la comunidad recomendamos en futuros estudios intentar el aislamiento viral a partir de las aguas residuales y realizar la caracterización genética mediante secuenciación de zonas seleccionadas de la región de las proteínas estructurales de los poliovirus aislados.

Es interesante señalar que los poliovirus detectados correspondieron a los serotipos 1 y 3 y no se identificaron poliovirus tipo 2. Una explicación a este fenómeno podría estar en relación con la formulación de la vacuna que se administra que es de 1000 000, 100000 y 600000 unidades (DICC 50) para los poliovirus tipo 1,2 y 3 respectivamente, con lo cual la concentración para el poliovirus 2 es baja y por ende predomina la excreción de los serotipos 1 y 3 .

En conclusión nuestros hallazgos indican la alta sensibilidad del sistema de vigilancia a partir de las aguas residuales para la detección de poliovirus, lo que permite considerar a las aguas residuales como una importante herramienta a emplear en las áreas del país en las cuales la vigilancia de las parálisis fláccidas es insuficiente o de mala calidad. Es significativo señalar que con el sistema de vigilancia actual no se han reportado casos de parálisis fláccida en los últimos años.

A pesar de que el municipio estudiado tiene coberturas altas de inmunización, en Colombia las coberturas de vacunación en los últimos 9 años han tenido una disminución importante sin lograr coberturas útiles, definidas como porcentajes por biológico iguales o superiores al 95 \% (23). En el análisis de áreas de riesgo para polio, se ha encontrado que al mes de julio del 2003, de los 1115 municipios del país solamente 256 (22,9 \%) tienen coberturas útiles de vacunación con OPV, pero hay 528 (47,3 \%) municipios en riesgo y 331 (29,6 \%) críticos. En el caso de que poliovirus derivados de la vacuna estén presentes en la región estos indicadores constituyen un riesgo para que se produzcan brotes por estos agentes. De esta manera el método propuesto en este trabajo se convertiría en la única herramienta útil para conocer las características de los poliovirus circulantes y de esta forma poder evitar el riesgo de futuras epidemias * 


\section{REFERENCIAS}

1. Pallansch M, Raymond P. Enteroviruses: polioviruses, coxsackieviruses, echoviruses and newer enterovirus. In: Knipe D, Howley P, Griffin D, eds. Fields Virology. 3th ed. Philadelphia, Pa: Lippincott Raven Publisher; 2001 p.123-775.

2. World Health Assembly. Global eradication of poliomyelitis by the year 2000 . Geneva: World Health Organization; 1988 (resolution 41.28).

3. World Health Organization. Report of the interim meeting of the Technical Consultation Group on the global eradication of poliomyelitis, WHO/EPI/GEN/02. World Health Organization, Geneva; 2002.

4. Kew OM, Nottay BK. Evolution of the oral poliovaccines strains in humans occurs by both mutation and intermolecular recombination. In: Chanock R, Lerner R, eds. Modern approaches to vaccines. New York: Cold Spring Harbor; 1984 p. 357-62.

5. WHO. Circulation of a type 2 vaccine-derived poliovirus, Egypt. WER. 2001; 76:27-9.

6. WHO. Outbreak of poliomyelitis-Dominican Republic and Haiti, 2000-2001. MMWR 2001;50:147-8.

7. WHO. Acute flaccid paralysis associated with circulation vaccine-derived poliovirus, Philippines, 2001. WER 2001;76:319-20.

8. WHO. Paralytic poliomyelitis in Madagascar, 2002. WER 2002;77:241-2.

9. Mas P, Gary H, Sarmiento L, Caceres V, Barrios J, Palomera R, et al. Poliovirus detection in wastewater and stool following an immunization campaign in Havana, Cuba. Int J Epidemiol 2003;32:772-7.

10. Sobsey M. Methods for recovering viruses from shellfish, seawater and sediments. In: Methods for recovering viruses in the enviroments. Boca de Ratón, FL: CRC Press; 1987 p.77-108.

11. Shieh YS, Wait D, Tai L, Sobsey MD. Methods to remove inhibitors in sewage and other fecal wastes for enterovirus detection by the polymerase chain reaction. J Virol Methods 1995;54:51-6.

12. Kilpatrick DR, Nottay B, Yang CF, Yang SJ, Mulders M, Holloway B, et al. Group-specific identification of polioviruses by PCR using primers containing mixed-base or deoxyinosine residues at positions of codon degeneracy. J Clin Microbiol 1996;34:2990-6.

13. Kilpatrick DR, Nottay B, Yang SJ, Da Silva E, Peñaranda S, Pallansch M, et al. Serotype-specific identification of polioviruses by PCR using primers containing mixed-base or deoxyinosine residues at positions of codon degeneracy. J Clin Microbiol 1998;36:352-7.

14. Yang CF, Lina De, Holloway BP, Pallansch MA, Kew OM. Detection and identification of vaccine related polioviurus by the Polymerase Chain Reaction. Virus Research 1991;20:159-79.

15. Kitchin PA, Bootman YS. Quality control of polymerase chain reaction. Rev Med Virol 1993;3:107-14. 
16. Sarmiento L, Mas P, Avalos I, Palomera R, Barrios J, Bello M. Evaluation of a new technology for the detection of enterovirus in sewage. Rev Cub Med Trop 1999;51:166-71.

17. Walter R, Maureen EB. The biological principles of poliovirus eradication. J Infect Dis 1997;175:286-92.

18. Bottiger M, Herrstron E. Isolation of poliovirus from sewage and their characteristics: experience over two decades in Sweden. Scand JID 1992;24:1515.

19. Minor PD, Ferguson M, Icenogle JP. Antigenic and molecular evolution of the vaccine strain of type 3 poliovirus during the period of excretion by a primary vaccine. J Gen Virol 1986;67:693-706.

20. Atmar RL, Metcalf TG, Neill FH. Estes MK. Detection of enteric viruses in oysters by using the polymerase chain reaction. Appl Environ Microbiol 1993;59:631-5.

21. Contreras G, Dimok K, Furesz J. Genetic characterization of Sabin types 1 and 3 poliovaccine virus following serial passage in the human intestinal tract. Biologicals 1992;20:15-26.

22. Sosa-Díaz R, Más P, Valdés O, Sarmiento L. Genetic changes in strains of poliovirus type 2 isolated from patients with vaccine-associated paralytic poliomyelitis. Rev Neurol 2003;36:812-6.

23. Instituto Nacional de Salud de Colombia. Evaluación del plan de erradicación de la poliomielitis en Colombia, año 2003 (semanas 1-35). Sivigila. Semana Epidemiológica No. 35; Agosto 24 al 30 de 2003. 